\title{
Distribution of Human Papillomavirus Genotypes among Women in Mashhad, Iran
}

\author{
Eskandar Taghizadeh ${ }^{\mathrm{a}, \mathrm{c}}$ Forough Taheri $^{\mathrm{d}}$ Hamed Abdolkarimi ${ }^{\mathrm{e}}$ \\ Pedram Ghorbani Renani ${ }^{d}$ Seyed Mohammad Gheibi Hayat ${ }^{b}$ \\ Departments of a Medical Genetics and b Medical Biotechnology, Faculty of Medicine, Mashhad University of \\ Medical Sciences, Mashhad, 'Cellular and Molecular Research Center, Yasuj University of Medical Sciences, Yasuj, \\ dSharekord Branch, Islamic Azad University, Sharekord, and e Department of Biology, Science and Research Branch, \\ Islamic Azad University, Tehran, Iran
}

\section{Keywords}

Human papillomavirus · Cervical cancer · Genotyping · Vaccine

\begin{abstract}
Objective: Cervical cancer is the third most common malignancy in females. Since the human papillomavirus (HPV) genotype can vary geographically, it is essential to define its genotypic distribution before establishing health care policies and vaccination programs in any given area. The aim of this study was to determine the frequency of HPV types in women in Mashhad, Iran. Methods: We used nested PCR and reverse dot-blot hybridization for genotyping. The study included 143 cervical cytology samples from Mashhad with confirmed papillomavirus infection by molecular methods. Results: We found that $74.1 \%$ of HPV types were in high-risk groups, including genotypes $16,18,39,52,58,66,68$, and 73 . Coinfection was detected in $56.4 \%$ of the cases. The low-risk group, comprising 25.9\%, included genotypes 6, 11, 42, and 44/55. Conclusions: Prevention, early diagnosis, and early treatment have been proven to reduce the mortality rate of cervical cancer. Therefore, an accurate diagnosis of the genotype of the virus in infected patients is very important.
\end{abstract}

(c) 2017 S. Karger AG, Basel (c) 2017 S. Karger AG, Basel

\section{KARGER}

E-Mail karger@karger.com

www.karger.com/int

\section{Introduction}

Human papillomavirus (HPV) is a large family of DNA tumor viruses best known for causing benign epithelial proliferative lesions or warts. Overall, there are currently more than 200 varied types of HPV, including about 30 strains that lead to infection in the human genital tract. Nowadays, human genital infections caused by HPV are common sexually transmitted diseases. The average global prevalence of HPV infection has been reported to be almost $10 \%$ (in the range of $1.4-25.6 \%$ ). This group of viruses consists of low-risk HPVs that do not cause cancer but can cause skin warts (genotypes 6, 11, 42 , and 44), and high-risk HPVs that cause cancer (genotypes $16,18,26,31,33,35,39,45,51,52,53,56,58,59,66$, $68,73,82)$. Neoplastic and cervical cancer may occur due to exposure to high-risk HPV infection. HPV is positive in approximately $100 \%$ of patients with cervical cancer based on epidemiological studies [1-6].

Three vaccines against HPV infection and disease have been available since 2006 [1]. A quadrivalent HPV 6/11/ 16/18 vaccine was approved in 2006 and a bivalent HPV $16 / 18$ vaccine was introduced in Europe in the following year. The EU issued a permit for a nonavalent HPV $6 / 11 / 16 / 18 / 31 / 33 / 45 / 52 / 58$ vaccine in 2015 .

Seyed Mohammad Gheibi Hayat

Faculty of Medicine, Mashhad University of Medical Sciences PO Box 91775-1365

Mashhad (Iran)

E-Mail gheibihm941@mums.ac.ir 
It should be noted that different regions in the world show specific prevalences and distributions of HPV, so that the region can determine the significance of different types of HPV [7-11]. The most prevalent species responsible for cervical cancer are types 16 (accounting for about $50 \%$ of cases), 18, 31, and 45 in the USA and Europe [12]. Types $52,16,58,68$, and 33 have the greatest prevalence among the population of South China [13].

It is necessary to identify the genotypic distribution of HPV before making a decision concerning public health policies and preparing vaccines in every region because, as mentioned, the type of HPV can be locally specific [14, 15]. To this end, a successful approach can use molecular techniques to detect HPV types in detail, even based on regional distributions. Hence, the current research was conducted to study the frequency of HPV types among females in Mashhad, Iran.

\section{Materials and Methods}

This was an observational and descriptive study based on all samples collected from hospitals and clinical centers in Mashhad, Iran, from March 2015 to April 2016. Our study protocol was approved by the local ethics committee of the Mashhad University of Medical Sciences. All participants were Iranian women living in Mashhad, which is located in the northeastern region of Iran. After obtaining written informed consent, a sampling of cells was taken from the cervical area using a swab. The sample was then placed into a bottle containing saline to be used for HPV testing. All participants were women with low-grade squamous intraepithelial lesions.

\section{Detection of HPV DNA}

The investigation of HPV DNA was performed in the molecular microbiology laboratories of the Department of Medical Microbiology, Mashhad University of Medical Sciences. From each cervical sample, cells were collected by ultracentrifugation and stored at $-20^{\circ} \mathrm{C}$ until DNA analysis. Extraction of the total DNA was carried out with the QIAamp DNA Minikit (Qiagen, Germany) according to the manufacturer's instructions. Subsequently, $10 \mu \mathrm{L}$ of nucleic acid was used to detect HPV DNA by nested PCR (polymerase chain reaction; Pars Toos Kit, Tehran, Iran) utilizing a thermal cycler. For the first amplification step, a combination of degenerate primers was used to amplify a 449- to 458-bp sequence within the L1 open reading frame of the HPV genome, which represents the most conserved gene within the genome. For the second step of the nested PCR, biotinylated primers were used to amplify a 139- to 145 -bp sequence. For each PCR, primers for $\beta$-globin were used as an internal control to ensure that all samples were amplified and there were no PCR inhibitors. For every 10 samples of each PCR, a negative control $\left(\mathrm{H}_{2} \mathrm{O}\right)$ and a positive control were run to exclude possible contamination and to determine the accuracy. Following amplifications, the PCR products were visualized by ethidium bromide staining after electrophoretic migration through $1.5 \%$ agarose gel
Table 1. Demographic characteristics of the study population

\begin{tabular}{|c|c|}
\hline \multicolumn{2}{|l|}{ Age } \\
\hline $20-30$ years & $31(21.7)$ \\
\hline $30-40$ years & $49(34.2)$ \\
\hline $40-50$ years & $42(29.4)$ \\
\hline $50-60$ years & $21(14.7)$ \\
\hline \multicolumn{2}{|l|}{ Education } \\
\hline No education & $8(5.6)$ \\
\hline Primary education & $21(14.7)$ \\
\hline High school & $73(51.0)$ \\
\hline University & $41(28.7)$ \\
\hline \multicolumn{2}{|l|}{ Smoking } \\
\hline Current smoker & $21(14.7)$ \\
\hline Former smoker & $9(6.3)$ \\
\hline Never smoked & $112(78.3)$ \\
\hline Unknown & $1(0)$ \\
\hline \multicolumn{2}{|l|}{ Marital status } \\
\hline Single & $18(12.6)$ \\
\hline Married & $111(77.6)$ \\
\hline Divorced & $14(9.8)$ \\
\hline \multicolumn{2}{|c|}{ Number of lifetime sex partners } \\
\hline 0 & $18(12.6)$ \\
\hline 1 & $120(83.9)$ \\
\hline $1+$ & $5(3.5)$ \\
\hline \multicolumn{2}{|l|}{ Menopause } \\
\hline Premenopause & $108(75.6)$ \\
\hline Postmenopause & $35(24.4)$ \\
\hline \multicolumn{2}{|l|}{ BMI } \\
\hline Mean (SD) & $23.2(4.8)$ \\
\hline Median (range) & $22.4(16.1-48.7)$ \\
\hline \multicolumn{2}{|l|}{ Contraception use } \\
\hline Yes & $82(57)$ \\
\hline No & $61(43)$ \\
\hline
\end{tabular}

Values in parentheses are percentages unless otherwise stated.

and were readily identified on the basis of the corresponding length of the amplicons. Finally, the positive samples were selected for the next step.

\section{Genotyping of $H P V$}

Genotyping was performed on HPV DNA-positive samples by a microbiologist. The method was a reverse dot blot hybridization assay (hybriSpot 12 ${ }^{\mathrm{TM}} ; \mathrm{HS} 12$ ) and contained specific probes for the 36 most frequent HPV types. Based on their association with different grades of lesions, HPV that can induce carcinogenesis has been classified as high risk or oncogenic, while low-risk HPVs are those which cause genital warts and collaborate with high-risk HPVs. The HPV Direct Flow CHIP is intended for the simultaneous screening and genotyping of 18 high-risk genotypes (HPV16, $18,26,31,33,35,39,45,51,52,53,56,58,59,66,68,73$, and 82 ) and 4 low-risk genotypes (HPV6, 11, 42, and 44/45) by PCR, followed by reverse dot-blot hybridization that is based on DNA flow technology (semi-automated hybriSpot $12^{\mathrm{TM}}$ and automated hybriSpot $24^{\mathrm{TM}}$ ) [16]. Finally, descriptive statistics were used to determine the distribution of HPV. 


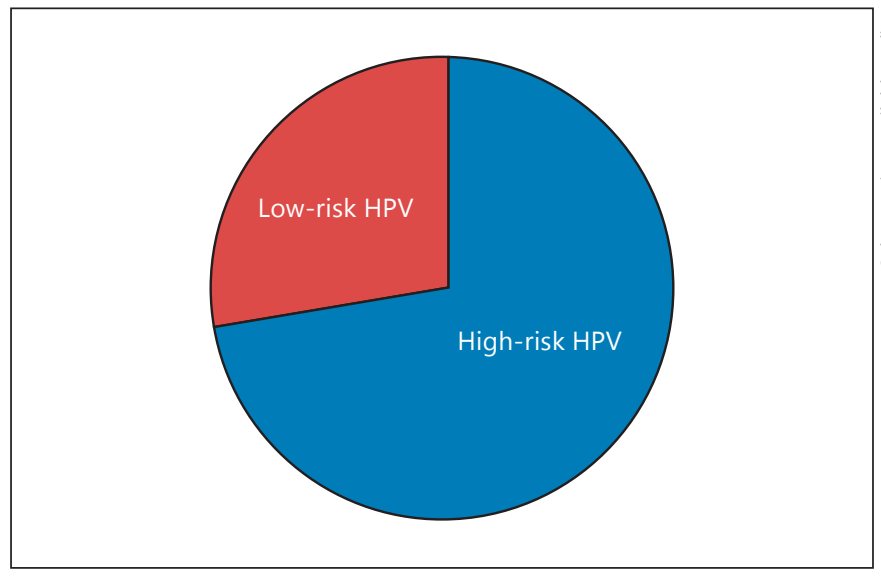

Fig. 1. Distribution of high- and low-risk HPV in the population.

\section{Results}

\section{Demographic Characteristics}

Mixed infections with 2 or more types of HPV were seen in some of our 143 samples and 184 genotypes. Table 1 shows the demographic details of the patients. The participants in the present research included 143 females with a mean age of 34.9 years (SD 6.9, range 20-52), in which a premenopausal status and history of previous pregnancy were recorded for about $75 \%$.

\section{HPV Prevalence and Genotypic Distribution}

Figure 1 presents the prevalence of the high- and lowrisk HPVs. According to the present findings, 48 (56.4\%) cases had coinfection among 85 subjects placed in the high-risk group. Of the 143 women who participated in the study, the total prevalence of HPV was $26 \%$ in the low-risk group and $74 \%$ in the high-risk group (Fig. 2). It should be noted that the most frequent high-risk HPV types were $16(38.6 \%), 18(14.7 \%), 39(3.8 \%), 52(3.8 \%)$, $58(3.3 \%), 73(3.3 \%), 45(2.1 \%), 66(2.1 \%)$, and $68(2.1 \%)$. The low-risk HPV subtypes were 6 (11.9\%), 42 (7.0\%), 11 (3.8\%), and 44/55 (3.3\%).

\section{Discussion}

In the present study, we could determine the distribution of HPV types in Mashhad, Iran. According to the results, approximately $74.1 \%$ of subjects were placed in the high-risk group.

A study in Eastern Africa reported that the most common worldwide HPV types are, respectively, 16, 18, 31,

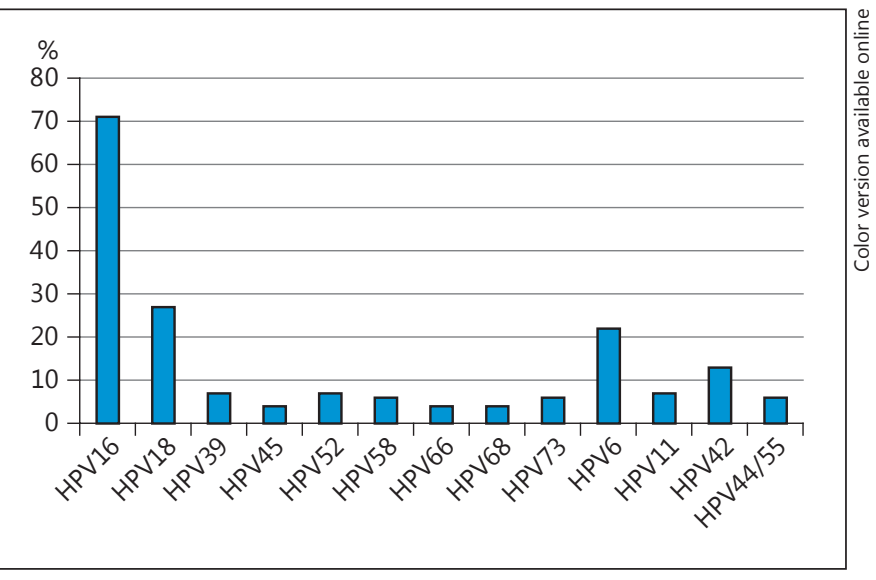

Fig. 2. HPV type distribution.

58, 52, and 66 among females [17]. HPV 16 and HPV 18 were the most prevalent genotypes in the current study area. HPV16 has the highest potential for carcinogenesis and is the key candidate for common HPV vaccines [18].

Epidemiological studies report single and multiple infections caused by HPV16 and HPV18 as high-risk viruses in about $75 \%$ of cervical cancers [19]. In addition, some other cancers, including vaginal, vulvar, anal, and throat, have been found to be due to these viruses. The absence of appropriate screening in developing countries has caused the rate of cervical cancer to rise. High-risk HPV s represent one of the leading reasons for developing cervical cancer, which means that the development from lesions to cancer can be prevented with the help of early and rapid therapeutic actions against the virus. The benefit of screening for this group of infections is clearly apparent [20]. Ku et al. [21] investigated the impact of genotypes on the severity and prognosis of cervical neoplasia, which showed the influence of the virus type on the severity of disease. HPV 18 was the most common HPV in their study, but was the second most frequent type in the present study, indicating the divergence of HPV prevalence in differing areas [22].

In 2002, during a multicenter study conducted in 7 countries, Muñoz et al. reported that HPV16 was the most common type (between 43.9 and $72.4 \%$ ) without exception [23]. In line with our study, the most frequently found HPVs in cervical carcinoma cases were HPV 16 (accounting for over 50\%) and HPV18 (12\%) in numerous reports [24]. Mahmoudi et al. [25] studied the role of HPV genotypes in cervical cancer in Yazd, Iran, and observed a high frequency of HPV16 (70\%) and HPV18 (16.7\%), followed by types 33,45 , and 73 , respectively
40

Intervirology 2017;60:38-42

DOI: $10.1159 / 000477848$
Taghizadeh/Taheri/Abdolkarimi/ Ghorbani Renani/Gheibi Hayat 
[26]. These findings are consistent with our study. To confirm our study further, a comprehensive genotyping performed on 20,000 Pap smear samples among patients in Kerman, Iran, showed that the HPV types 16 and 18 had the greatest frequency [27].

There are several reasons for continuing HPV vaccination as a successful approach in Iran. These include the possible cross-protection of vaccines versus nonvaccine HPV types. Also, many infections that evade the vaccine target range are transient and cannot cause cervical cancer. This indicates a certain prevention strategy in settings like Iran with very narrow resources and weak cervical cancer screening coverage. Taking the results obtained from our study on HPV prevalence and genotype distribution in Mashhad as a baseline might be the first step in monitoring the dynamics of the distribution of the HPV genotype following HPV vaccination. This could be ascribable before alteration in precancerous cervical lesions, which needs to be routinely monitored over time. Nevertheless, the continued collection of data on baseline HPV type prevalence in Mashhad patients is necessary so that the efficacy of the HPV vaccine can be monitored in the long term $[7,18,28,29]$.

Several limitations to the present study should be considered. First is a lack of cytological evaluation that led to more sample stratification. Also, a lack of amplification of all genotypes with identical sensitivity to primers could have been a source of variance in genotype detection. A final limitation was failure to assess the influence of the HPV vaccine. According to health economic models that consider potential advantages, a cost-benefit might be seen following HPV vaccination programs in Iran.

\section{Conclusion}

This study showed that infections with some types of viruses are common in HPV-positive women. In this study, we diagnosed different types of HPV and, consistent with other published studies, showed that HPV16 was the most abundant. This result is important for the selection of prevention strategies and improving approaches to combating cervical cancer.

\section{Disclosure Statement}

The authors have no conflicts of interest to declare.

\section{References}

1 Arbyn M, Castellsagué X, de Sanjosé S, Bruni L, Saraiya M, Bray F, et al: Worldwide burden of cervical cancer in 2008. Ann Oncol 2011; 22:2675-2686.

2 Clifford G, Smith JS, Plummer M, Munoz N, Franceschi S: Human papillomavirus types in invasive cervical cancer worldwide: a metaanalysis. Br J Cancer 2003;88:63-73.

3 Parkin DM: Global cancer statistics in the year 2000. Lancet Oncol 2001;2:533-543.

4 Shen Z, Liu X, Morihara J, Hulbert A, Koutsky LA, Kiviat NB, et al: Detection of human papillomavirus infections at the single-cell level. Intervirology 2016;58:324-331.

5 Burd EM: Human papillomavirus and cervical cancer. Clin Microbiol Rev 2003;16:1-17.

6 Clifford G, Gallus S, Herrero R, Munoz N, Snijders P, Vaccarella S, et al: Worldwide distribution of human papillomavirus types in cytologically normal women in the International Agency for Research on Cancer HPV prevalence surveys: a pooled analysis. Lancet 2005;366:991-998.

7 Franco EL, Harper DM: Vaccination against human papillomavirus infection: a new paradigm in cervical cancer control. Vaccine 2005; 23:2388-2394.

Distribution of HPV Genotypes
8 Joura EA, Giuliano AR, Iversen OE, Bouchard C, Mao C, Mehlsen J, et al: A 9-valent HPV vaccine against infection and intraepithelial neoplasia in women. New Engl J Med 2015; 372:711-723.

9 Smith JS, Lindsay L, Hoots B, Keys J, Franceschi S, Winer R, et al: Human papillomavirus type distribution in invasive cervical cancer and high-grade cervical lesions: a meta-analysis update. Int J Cancer 2007;121:621-632.

10 Tamalet C, Ravaux I, Dhiver C, Menard A, Colson P, Stein A: Feasibility and acceptability of anal self-sampling for human papillomavirus screening in HIV-infected patients. Intervirology 2016;59:118-122.

11 Joura E, Pils S: Vaccines against human papillomavirus infections: protection against cancer, genital warts or both? Clin Microbiol Infect 2016;22:S125-S127.

12 Harro CD, Pang YY, Roden RB, Hildesheim A, Wang Z, Reynolds MJ, et al: Safety and immunogenicity trial in adult volunteers of a human papillomavirus $16 \mathrm{~L} 1$ virus-like particle vaccine. J Natl Cancer Inst 2001;93:284-292.

13 Li J, Huang R, Schmidt JE, Qiao Y-L: Epidemiological features of human papillomavirus (HPV) infection among women living in Mainland China. Asian Pac J Cancer Prev 2013;14:4015-4023.
14 Bruni L, Diaz M, Castellsagué M, Ferrer E, Bosch FX, de Sanjosé S: Cervical human papillomavirus prevalence in 5 continents: metaanalysis of 1 million women with normal cytological findings. J Infect Dis 2010;202:17891799 .

15 De Sanjosé S, Diaz M, Castellsagué X, Clifford G, Bruni L, Muñoz N, et al: Worldwide prevalence and genotype distribution of cervical human papillomavirus DNA in women with normal cytology: a meta-analysis. Lancet Infect Dis 2007;7:453-459.

16 Herraez-Hernandez E, Alvarez-Perez M, Navarro-Bustos G, Esquivias J, Alonso S, Aneiros-Fernandez J, et al: HPV Direct Flow CHIP: a new human papillomavirus genotyping method based on direct PCR from crudecell extracts. J Virol Methods 2013;193:9-17.

17 Insinga RP, Liaw KL, Johnson LG, Madeleine MM: A systematic review of the prevalence and attribution of human papillomavirus types among cervical, vaginal, and vulvar precancers and cancers in the United States. Cancer Epidemiol Biomarkers Prev 2008; 17: 1611-1622. 
18 Cutts F, Franceschi S, Goldie S, Castellsague X, de Sanjose S, Garnett G, et al: Human papillomavirus and HPV vaccines: a review. Bull World Health Organ 2007;85:719-726.

19 Harper DM, Franco EL, Wheeler C, Ferris DG, Jenkins D, Schuind A, et al: Efficacy of a bivalent $\mathrm{L} 1$ virus-like particle vaccine in prevention of infection with human papillomavirus types 16 and 18 in young women: a randomised controlled trial. Lancet 2004;364: 1757-1765.

20 Koutsky L: Epidemiology of genital human papillomavirus infection. Am J Med 1997; 102:3-8.

$21 \mathrm{Ku}$ C-H, Lee SH, Lee SP: Effect of human papillomavirus genotype on severity and prognosis of cervical intraepithelial neoplasia. Obstet Gynecol Sci 2014;57:37-43.
22 Vu LT, Bui D, Le HT: Prevalence of cervical infection with HPV type 16 and 18 in Vietnam: implications for vaccine campaign. BMC Cancer 2013;13:53.

23 Castellsagué X, Díaz M, De Sanjosé S, Muñoz N, Herrero R, Franceschi S, et al: Worldwide human papillomavirus etiology of cervical adenocarcinoma and its cofactors: implications for screening and prevention. J Natl Cancer Inst 2006;98:303-315.

24 Vinodhini K, Shanmughapriya S, Das BC, Natarajaseenivasan K: Prevalence and risk factors of HPV infection among women from various provinces of the world. Arch Gynecol Obstet 2012;285:771-777.

25 Mahmoudi S, Hamkar R, Akhavan TM, Eslamifar A, Adibi L, Sadrabadi A, Nategh R: Determination of human papilloma virus genotypes in cervical cancer specimens, in Yazd province. Iran J Infect Dis Trop Med 2007;12:19-24.
26 Jalilvand S, Shoja Z, Hamkar R: Human papillomavirus burden in different cancers in Iran: a systematic assessment. Asian Pac J Cancer Prev 2014;15:7029-7035.

27 Afshar RM, Mollaie HR, Fazlalipour M, Arabzadeh SA: Prevalence and type distribution of human papillomavirus infection using the INNo-Lipa assay, Kerman, Southeast Iran. Asian Pac J Cancer Prev 2013;14:52875291.

28 La Torre G, de Waure C, Chiaradia G, Mannocci A, Ricciardi W: HPV vaccine efficacy in preventing persistent cervical HPV infection: a systematic review and meta-analysis. Vaccine 2007;25:8352-8358.

29 Palefsky JM, Giuliano AR, Goldstone S, Moreira Jr ED, Aranda C, Jessen H, et al: HPV vaccine against anal HPV infection and anal intraepithelial neoplasia. New Engl J Med 2011;365:1576-1585. 